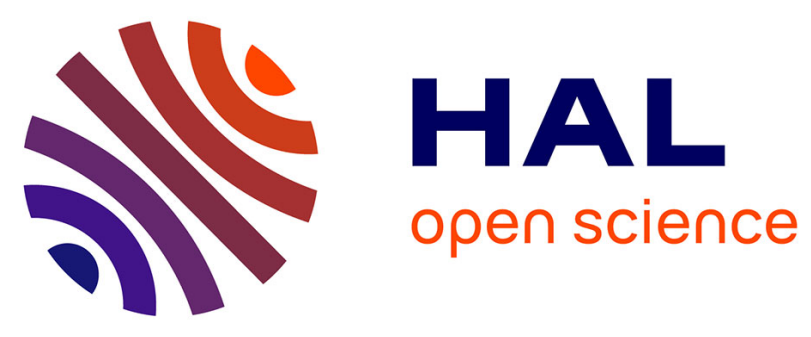

\title{
Root traits of herbaceous crops: Pre-adaptation to cultivation or evolution under domestication?
}

Nieves Martín-Robles, Javier Morente-López, Gregoire Freschet, Hendrik Poorter, Catherine Roumet, Rubén Milla

\section{- To cite this version:}

Nieves Martín-Robles, Javier Morente-López, Gregoire Freschet, Hendrik Poorter, Catherine Roumet, et al.. Root traits of herbaceous crops: Pre-adaptation to cultivation or evolution under domestication?. Functional Ecology, 2018, 33 (2), pp.273-285. 10.1111/1365-2435.13231 . hal-02309651

\section{HAL Id: hal-02309651 \\ https://hal.science/hal-02309651}

Submitted on 9 Oct 2019

HAL is a multi-disciplinary open access archive for the deposit and dissemination of scientific research documents, whether they are published or not. The documents may come from teaching and research institutions in France or abroad, or from public or private research centers.
L'archive ouverte pluridisciplinaire HAL, est destinée au dépôt et à la diffusion de documents scientifiques de niveau recherche, publiés ou non, émanant des établissements d'enseignement et de recherche français ou étrangers, des laboratoires publics ou privés. 


\section{Functional Ecology}

DR NIEVES MARTÍN-ROBLES (Orcid ID : 0000-0002-3227-0289)

MR JAVIER MORENTE-LÓPEZ (Orcid ID : 0000-0001-9141-8581)

DR GRÉGOIRE THOMAS FRESCHET (Orcid ID : 0000-0002-8830-3860)

Article type : Research Article

Editor : Mark Tjoelker

Section : Plant Morphology

\section{Root traits of herbaceous crops: pre-adaptation to cultivation or evolution under domestication?}

Nieves Martín-Robles ${ }^{1 *}$, Javier Morente-López ${ }^{1}$, Grégoire T. Freschet ${ }^{2}$, Hendrik Poorter $^{3}$, Catherine Roumet ${ }^{2}$, Rubén Milla ${ }^{1}$

${ }^{1}$ Departamento de Biología y Geología, Área de Biodiversidad y Conservación, Escuela Superior de Ciencias Experimentales y Tecnología, Universidad Rey Juan Carlos, c/Tulipán s/n, Móstoles 28933, Spain;

2 CEFE, CNRS, Université de Montpellier, Université Paul Valéry Montpellier 3, EPHE, IRD, Montpellier, France;

${ }^{3}$ Plant Sciences (IBG-2), Forschungszentrum Jülich GmbH, D-52425 Jülich, Germany

*Corresponding author: Nieves Martín-Robles, nievesmartin@msn.com

This article has been accepted for publication and undergone full peer review but has not been through the copyediting, typesetting, pagination and proofreading process, which may lead to differences between this version and the Version of Record. Please cite this article as doi: 10.1111/1365-2435.13231

This article is protected by copyright. All rights reserved. 


\section{SUMMARY}

1. Agricultural fields are commonly characterized by high nutrient and water availabilities, which are favorable for plant growth. Such conditions might promote the evolution of resource acquisitive strategies. We asked whether crop plants show root traits typical of resource acquisitive strategies and whether this strategy is primarily a result of their evolution under domestication or of the early selection of successful candidates for domestication.

2. We studied a set of 30 crop species and their wild progenitors. We set up a greenhouse experiment to measure five root traits: root thickness, root tissue density, specific root length (SRL), root mass fraction (RMF) and root length ratio. In addition, we compiled data from other wild herbaceous species, growth in similar conditions to this experiment, to place the root traits of our crops in the context of wider botanical variation.

3. Wild progenitors had thicker and less dense roots, with higher RMF and lower SRL, than other wild herbs. Thicker and less dense roots are indicative of fertile soils, which suggests that wild progenitors could have been adapted for success in agricultural conditions. Additionally, we found that domestication generally increased total plant dry mass, but none of the root traits evolved consistently towards a more resource-acquisitive strategy after domestication across all species. Root trait values differed between progenitors and crop species for most pairs surveyed, but this occurred in diverse directions depending on crop species.-Such differences were independent of phylogeny, functional group or variability in the domestication processes, such as timing of the domestication event or organ under focal artificial selection. 
4. Our comparative study revealed that the root phenotype exhibited by wild progenitors (thick roots with low density and SRL), when compared with other wild herbs, was in accordance with plants typical from fertile habitats. However, none of the root traits reacted to domestication in accordance with evolution towards fast-growth strategies. Thus, the adaptation of crop root phenotypes to the fertile conditions of agricultural fields might be largely determined by early choices of wild species, rather than by further evolution under domestication.

\section{KEY-WORDS}

Crop progenitors, domestication, functional traits, origins of agriculture, plant resource economics, root economics spectrum, root tissue density, specific root length.

\section{INTRODUCTION}

Plant domestication involves selection for and modification as well as long-term use of traits regarded as favorable by humans in wild species (Evans, 1996; Gepts, 2004). Major changes commonly associated with artificial selection include yield increase of the organs of interest (e.g. seeds or fruits), strong apical dominance, and loss of seed dispersal and seed dormancy mechanisms (Evans, 1996; Gepts, 2004; Abbo et al., 2014). The consequences of crop domestication on plant traits also include the decline in herbivore defense (Turcotte, Turley \& Johnson, 2014; Whitehead, Turcotte \& Poveda, 2016), higher stomatal densities at the upper side of leaves (Milla, de DiegoVico \& Martín-Robles, 2013) or the nitrogen and phosphorus concentration increase in leaves (Delgado-Baquerizo, Reich, García-Palacios, \& Milla, 2016). Some consequences of crop domestication, such as higher leaf nitrogen contents (DelgadoBaquerizo, Reich, García-Palacios, \& Milla, 2016) and higher relative growth rates 
(Preece et al., 2017), would be typical of fast-growing resource-acquisitive strategies (Lambers \& Poorter, 1992; Craine, 2009; Reich, 2014). Thus, domestication might have led to the evolution towards fast-growing plants with resource-acquisitive strategies in response to agricultural conditions (Chapin, 1980; Craine, 2009; Milla, Osborne, Turcotte, \& Violle, 2015).

One obvious cause of these domestication effects is recurrent natural selection by the farmers (Denison Kiers \& West, 2003; Zohary, 2004; Milla, Osborne, Turcotte, \& Violle, 2015). Such selection in agricultural fields might have led to adaptations in above and belowground traits, because croplands differ from wild habitats in the availability of resources (nutrients and water), or in the intensity and frequency of disturbances (Mckey, Elias, Pujol, \& Duputié, 2012; Milla, Osborne, Turcotte, \& Violle, 2015). Nevertheless, an alternative would be that wild progenitors may also have shown acquisitive strategies before domestication started. Human society has been shaping the ecosystems around their settlements before agriculture started changing the environment (Smith, 2007). The new environmental conditions would be characterized by high fertility and increase in the frequency of disturbances (fires, selective plant culling) and would therefore have led to the modification of diversity, enhancing the short-term productivity of herbaceous plants (Smith, 2011). The 'Dump Heap' hypothesis suggests that early domestication started with species growing near human settlements (Sauer, 1952; Zeven, 1973; Hawkes, 1983). If so, successful candidates of domesticated species would be pre-adapted to cultivation conditions (Hawkes, 1983) with ruderal, generalist and fast-growing characteristics (Mercuri, Fornaciari, Gallinaro, Vanin, \& di Lernia, 2018). In support of this idea, a few studies have shown greater seed mass, faster growth rates, greater specific leaf areas, and greater nitrogen 
concentrations in wild progenitors in comparison with other wild species, which fits with fast-growing strategies for crops' ${ }^{\prime}$ ancestry (Cunniff et al., 2014; Milla, Osborne, Turcotte, \& Violle, 2015; Preece et al., 2015). Thus, theoretical and empirical evidences based on aboveground traits suggest that domesticated species have fast acquisitive strategies, either as a consequence of pre-adaptions to the agricultural environment and/or as evolution under cultivation. While our knowledge is pretty substantial when it comes to how domestication affected above-ground plant traits, we have only very limited insight into what happened below-ground. (Bishopp \& Lynch, 2015; Lynch \& Brown, 2012).

A diversity of physiological and morphological root traits has been put forward as indicative of root resource acquisitive strategies (see Freschet \& Roumet, 2017 for a review). The root length ratio (RLR; see Table 1 for abbreviations and definitions) and its determinants - root mass fraction (RMF), specific root length (SRL), mean root diameter (MRD) and root tissue density (RTD) - are among the most important morphological and allocational traits determining root nutrient acquisition capacity (Ryser \& Lambers, 1995). Fast acquisitive strategies are generally characterized by low structural investment in roots: low RMF, MRD and RTD (Ryser 1996). Poorter and Ryser (2015) suggested a general model of root trait coordination (Fig. 1a) where increasing soil fertility would result in larger plants, with thicker and less dense roots, with contrasting effects on SRL (see also Freschet, Swart, \& Cornelissen, 2015a). Overall, as fertility would decrease the proportion of biomass allocated belowground (RMF), the model predicts that, via indirect effects, RLR would generally decrease with fertility. Since agricultural and pre-agricultural environments are mostly fertile ecosystems (Denison, Kiers \& West, 2003; Mckey, Elias, Pujol, \& Duputié, 2012), one 
could therefore expect that crop evolution should have followed the pathway of phenotypic adjustments proposed by Poorter and Ryser (2015). If correct, novel agricultural conditions would trigger larger plants with higher MRD and lower RTD, implying contrasting impacts on SRL and, together with the lower RMF would determine the RLR.

In this study we investigated whether domesticated plants show root trait values typical of resource acquisitive strategies and whether this strategy is primarily a result of their evolution under domestication or of the early selection of successful candidates (or wild progenitors) for domestication. These questions will be tested by: i) comparing root traits of 30 domesticated species and their wild progenitors with root traits of other wild herbaceous species taken in global data bases, ii) examining the domestication effect on plant biomass and root traits and iii) testing whether the response of root traits to domestication is consistent with the causal model of Poorter and Ryser (2015). We hypothesized that i) wild progenitors already show trait values typical of plants adapted to fertile habitats, ii) domestication has a similar effect on root traits as fertility. Domestication would thus have selected larger plants with higher MRD, but lower RTD, lower SRL, and RMF values as compared to their progenitors which are expected to show more acquisitive root traits than other wild species. 


\section{MATERIALS AND METHODS}

\section{Study system}

To maximize the generality of our results, we worked with a phylogenetically diverse set of 30 herbaceous crop species and their most likely wild progenitors (Table 2). Our set of crops includes eight grasses, 11 legumes and 11 non-leguminous forbs, with different domestication geographies and histories. We obtained seed lots for each of these 30 crops: one belonging to an accession of a common domesticated cultivar and another from the most likely wild progenitor (Table 2). More information about the species and accessions (references of domesticated cultivar and wild progenitor assignment, seed donor banks accession identifier, time under domestication and organ under selection) can be found in Table S1. In addition, to place the root traits of wild progenitors and domesticated plants in the context of global herbaceous variation, we compiled root data from taxonomically diverse wild herbaceous species.

\section{Growth conditions}

For logistical reasons, the 30 crop pairs were grown staggered from January to June 2012, matching the most appropriate time of the year for the performance of each crop. The two accessions (domesticated plant and wild progenitor) belonging to each pair were simultaneously grown at the same spatial location within the greenhouse (located in Móstoles, central Spain, $\left.40^{\circ} 18^{\prime} 48^{\prime \prime} \mathrm{N}, 3^{\circ} 52^{\prime} 57^{\prime \prime} \mathrm{W}\right)$. To avoid plants from becoming severely pot-bound (Poorter, Bühler, Van Dusschoten, Climent, \& Postma, 2012), we built special long containers to allow the growth of root systems for several weeks before reaching the bottom of the container. A round plastic cylinder $(42 \mathrm{~cm}$ deep, $8 \mathrm{~cm}$ diameter) was embedded inside, and down to the bottom end of a $25 \mathrm{~cm}$ long Jumbo Rootrainer (Haxnicks Ltd., Wiltshire, UK), resulting in a final container of $42 \mathrm{~cm}$ depth x $50 \mathrm{~cm}^{2}$ area $(2.1 \mathrm{~L}$, Fig. S1). The bottom of this final container was removable without 
root or substrate disturbance, to analyze the depth of the deepest root (Fig. S1). Containers were filled with pure sand to facilitate recovery of the complete root system. Finally, plants were fertilized twice a week with $50 \mathrm{~mL}$ of a complete nutrient solution to allow normal development in the sandy substrate and watered through regular automatic water sprinkling as needed to maintain plants under optimal growth conditions.

\section{Plant root harvest and trait measurements}

Every second day we checked the depth of the roots in the container by opening the removable bottom. As soon as the roots of a given species reached the bottom of the container, the complete set of individuals belonging to a species pair were harvested. At that time, plants were 30 - 40 days old after germination, the exact time depended on the crop pair. We harvested 5-10 (median 9) healthy and well developed plants per accession (wild progenitor and domesticated plant), and carefully cleaned the whole root system. The whole root system of each individual was transferred to a transparent tray filled with water, where the root branches were carefully spread out to avoid overlapping. Then the root system was scanned as greyscale images at a resolution of 400 dpi (Epson scan GT 15000). Total root length (m), root mean diameter (mm), and root volume $\left(\mathrm{cm}^{3}\right)$ were determined for the whole root system using a scanner-based, digital image analysis system (WinRHIZO; Regents Instruments, Quebec City, Canada; Arsenault, Poulcour, Messier \& Guay, 1995). Following root scanning, roots and the aboveground part of each plant were oven dried $\left(60^{\circ} \mathrm{C}\right)$ and weighed to estimate: total plant dry mass (g), root tissue density (RTD, g root $\mathrm{ml}$ root), specific root length (SRL, $\mathrm{m}$ root $\mathrm{g}^{-1}$ root), root mass fraction ( $\mathrm{RMF}, \mathrm{g}$ root $\mathrm{g}^{-1}$ plant) and root length ratio (RLR, $\mathrm{m}$ root $\mathrm{g}^{-1}$ plant) (Table 1). A total of 527 plants were phenotyped. 


\section{Data gathering}

To test whether the roots of domesticated plants and wild progenitors were different to those of other wild herbaceous species, we compiled root data from two global databases of root traits of wild herbaceous species. In both databases, we selected data of herbaceous species from diverse botanical families and excluded data from tree species, crop species and species belonging to the same genus as our crops. In addition, the data selected from both databases belong to plants grown in conditions similar to our experiment: pots in controlled conditions (indoors or outdoors), to ensure the comparability with the data of the 30 domesticated plants and wild progenitors. The Rhizopolis-db, a global database of fine root traits (details in Freschet et al., 2017) was used for comparisons of MRD (145 species; 53\% forbs, 30\% grasses and 17\% legumes), RTD (141 species; 54\% forbs, 30\% grasses and 16\% legumes) and SRL (99 species; $43 \%$ forbs, 36\% grasses and $20 \%$ legumes). The RMF database (398 species; 49\% forbs, $42 \%$ grasses and 9\% legumes) was taken from Poorter et al. (2015).

\section{Statistical analyses}

Prior to hypotheses testing we imputed missing values $(1.6 \%)$, which were randomly distributed along the data, using multivariate imputations with chained equations (Nakagawa \& Freckleton, 2008; Penone et al., 2014) with the R package "mice" (Buuren \& Groothuis-Oudshoorn, 2011). In addition, five individuals with extreme trait values were excluded from the data. Finally, all subsequent analyses were ran with 522 individuals, and trait data were $\log _{10}$-transformed to meet normality assumptions and homogeneity of variance of models' residuals. All statistical analyses were performed with the R software (R Core Team, 2014). 
To test whether the roots of domesticated plants and wild progenitors were different to those of other wild herbaceous species, we performed phylogenetic generalized least squares models (PGLSs) comparing wild progenitors and domesticated species with databases of root traits of wild herbaceous species. The root traits: MRD, RTD, SRL and RMF were included as response variables in the PGLS models. Plant type (wild progenitor, domesticated plant or other wild species) was included as explanatory variable. Additionally, we analyzed whether differences in the root traits along plant types varied for grasses, legumes and forbs (functional group). For doing so, we included functional group and the interaction with plant type as explanatories in the models. PGLS models incorporate phylogenetic correlation structure in model residuals to account for phylogenetic non-independence of species data points (Symonds \& Blomberg, 2014). To run the PGLS regressions, we built a phylogenetic tree for each root trait containing the species of each database and the 30 crops pairs. To do so, each phylogenetic tree was derived from a largest reference tree of the angiosperms (Zanne et al., 2014), with the drop.tip function of 'phytools' package (Revell, 2012). Species not represented in the reference tree were replaced by other species of the same genus presented in the reference tree, only when there was one or two species representatives of the genus in the data set; or removed from the data sets when there were more species representing the genus. The resulting trees did not have polytomies. PGLSs were implemented using the gls function of the 'picante' package (Kembel et al., 2010). Finally, post hoc test with pairwise comparison among levels of the fixed effects factors and the interaction were conducted using the phylANOVA function of the 'phytools' package (Revell, 2012). 
To assess the effect of domestication on each root trait separately, we used linear mixed effect models. The dependent variables were the five root traits and total plant dry mass (TDM). In all models, domestication status (domesticated plant or wild progenitor) was included as fixed factor. Crop identity (30 crops, Table 2) was included as a random effect over the intercept of the model, and as a random effect over domestication status (random slope effect, analogous to an interaction term in fixed effects models). In addition, we analyzed whether domestication effects were different for grasses, legumes, and forbs. For doing so, we included functional group and its interaction with domestication status as fixed effect terms in the models. All models were run with the lme function of the "nlme" R package (Pinheiro et al., 2015). The significance of the fixed factors was tested with type III analysis of variance, with the mixed function of the 'afex' package (Singmann, Bolker, \& Westfall, 2015). The mixed function fits the complete model and creates reduced versions removing a single effect, then compares the reduced model to the complete model. In order to assess goodness of fit, we obtained the conditional $\mathrm{R}^{2}$ (variance explained by random and fixed factors) and marginal $\mathrm{R}^{2}$ (the variance explained by fixed factors) of the models following Johnson (2014), using the R package "MuMIn” (Bartón, 2013).

Finally, to test how domestication changed root traits and the consequences thereof for the whole root phenotype, we used the multivariate model proposed by Poorter and Ryser (2015), and tested it using path analyses (Shipley, 2009). The original model predicts the response of root traits to nutrient availability (Fig.1a), but since we hypothesized that evolution under domestication occurs in high fertility habitats (Denison, Kiers \& West, 2003), we replaced "nutrient availability" by "domestication status" (Fig. 1b). To test whether our data fit the Poorter and Ryser (2015) model, we 
conducted a phylogenetic confirmatory path analysis. Phylogenetic analysis was selected to account for non-independence of data due to phylogenetic relatedness of the crop species (González-Voyer \& Von Hardenberg, 2014). In phylogenetic path analysis, the predicted relationships between the variables are translated into models and analyzed using PGLS with phylogenetic signal (Pagel's lambda) estimated with maximum likelihood. To conduct the PGLS we built a phylogenetic tree. To do so, we pruned the large dated angiosperm phylogeny tree (Zanne et al., 2014) to our set of genera using the "phytools" R package (Revell, 2012). The significance of the paths was calculated using a d-sep approach (Shipley, 2009), based on an acyclic graph that depicts the hypothetical relationships and independence claims between variables. The d-seps are translated into models and analyzed using PGLS. Likewise, we assessed the goodness of fit of the data to the path model using the associated p-values with the Fisher's C statistic (Shipley, 2009). The standardized path coefficients were obtained from PGLS (Grace \& Bollen, 2005). In addition, we estimated the coefficients and significance of indirect and total effects of domestication on each trait in the path diagram (Grace \& Bollen, 2005). The indirect effects were calculated by multiplying all the path coefficients that link the domestication variable with each variable of the model, and total effects were computed as the sum of direct and indirect effects (Grace $\&$ Bollen, 2005). The significance of the total effects of domestication on each root trait was calculated with the sum of the variance associated to each direct and indirect effect. 


\section{RESULTS}

\section{Root functional differences between domesticated species, wild progenitors and}

other wild herbaceous species

To see how wild progenitors and domesticated plants were relative to wild species, we compared our data with large compilations from the literature. Wild progenitors and domesticated plants significantly differed from other wild herbaceous species for the four root traits analysed (plant type: $P<0.05$, Fig. 2), irrespective of functional group (functional group: $P>0.05$, Table S2). The wild progenitors and domesticated accessions of this experiment had thicker and less dense roots in comparison with the data from wild herbaceous species, with lower SRL scores, and greater allocation to root biomass (Fig. 2).

\section{Domestication and crop identity effects on TDM and root traits}

We found a general increase of total dry mass after domestication (Table 3, Fig. 3a). TDM ranged from 0.2-4 $\mathrm{g}$ for wild progenitors and 0.5-8 $\mathrm{g}$ for domesticated accessions (Table S3). The response to domestication varied among crops, as indicated by the variance associated with crop identity (Table 3). In addition, the response to domestication was more positively pronounced for larger wild progenitors (correlation term: crop identity $\mathrm{x}$ domestication status $=0.63$ ), such as bean or cucumber; and was even slightly negative for smaller progenitors, such as white clover or Rucola (Fig.3a). We also found a stronger response to domestication in legumes, which increased TDM after domestication more than grasses and forbs (Fig. 4a). 
None of the five root traits showed a significant response to domestication across species (Domestication effect $P>0.15$, Table 3 ). The variance associated with the random structure indicated a wide variability in the response to domestication among the 30 pairs of crops (Figs. 3b-f). For example, RMF increased with domestication in crops such as soybean or chickpea, but decreased in others such as cabbage or oat (Table S3, Fig. 3e). MRD, SRL, RMF and RLR was significantly affected by functional group (Table 3, Fig. 3b, d, e and f). Nevertheless, the response to domestication of each functional group was insignificant for the five root traits (interaction domestication status x functional group, Table 3, Figs. 4b-f).

\section{Multi-trait response of roots to domestication}

Plants increased their total dry mass in response to domestication (path $=0.27, P=$ 0.004, Fig. 1b). However, MRD, RTD and RMF were not directly affected by domestication ( $P>0.05$, Fig. 1b). The overall goodness of fit of the data to the theoretical model was high (C-statistic of 20.6 and associated $P$ 0.55, Fig. 1b). The relationships between TDM and root traits fitted the a priori model (Poorter \& Ryser, 2015; Fig. 1a), with the exception of the relationship between TDM and RTD (see significance and path scores in Fig. 1b). Larger plants had thicker fine roots (MRD, path $=0.33, P=0.003$, Fig. 1b). Both MRD and RTD had negative effects on SRL (path = 0.76 and $P<0.001$ for MRD; path -0.5 and $P<0.001$ for RTD, Fig. $1 b$ ) and RLR was more dependent on changes in SRL than in RMF (path $=0.95, P<0.001$, and path $=$ $0.27, P<0.001$, respectively, Fig. 1b). In line with univariate analyses, domestication had negligible effects on root traits via indirect effects. The positive effect on plant size driven by domestication was not strong enough to trigger significant net effects on MRD, RTD, SRL and RMF (Fig. 5). 


\section{DISCUSSION}

Based on the screening of root traits of a uniquely large set of crop species, our analyses revealed new correlates of plant domestication. Specifically, we found that the evolution towards larger plants during domestication implies correlated evolution of thicker roots. However, since (i) the direct effect of domestication on plant size and of plant size on root thickness were modest, and (ii) indirect effects are small, due to their multiplicative nature; the overall effect of domestication on root thickness was of small magnitude. Additionally, root trait responses to domestication were diverse among the several crop species. That variation was however unrelated to phylogenetic or peculiarities of domestication process of the 30 crops. More interestingly, we showed that root traits of domesticated plants and of their wild progenitors are not a random sample of global functional trait variation of other wild herbaceous species; they are biased towards trait scores indicative of plants adapted to highly fertile conditions. This result leads us to suggest that the crop root phenotypes, and their adaptability to agricultural habitats, were mainly determined by early selection of wild species which were already preadapted to highly fertile and frequently disturbed habitats, rather than by further evolution with domestication. These results have important implications for our understanding of resource acquisition strategies of crop roots and portend applied approaches to develop improved cultivars.

\section{The roots of crop wild progenitors were pre-adapted to agricultural conditions}

Current crop phenotypes are the outcome of centuries of selection under agriculture, but also reflect the choices of early farmers among available wild plants (Sauer, 1952; Preece et al., 2015; Mercuri, Fornaciari, Gallinaro, Vanin, \& di Lernia, 2018). Although crop evolution under domestication exerted a modest impact on root traits in our study, 
as discussed below, early farmers already showed a bias on root phenotypes of agricultural plants. Specifically, roots of crops' wild progenitors, in comparison with those of other wild herbs, were less dense and thicker (Fig. S2), which is typical of fastgrowing species from fertile habitats (Kramer-Walter et al., 2016; Reich, 2014; Ryser, 1996). Furthermore, thicker but less dense roots are suggested to be caused by roots with more cortex area than stele (xylem vessels) area, because cortex area is less dense (Kong et al., 2014). Species with such a root phenotype rely more on mycorrhizal associations for mineral nutrition (Brundrett, 2002; Ma et al., 2018) and indicate acquisitive strategies (Kong et al., 2016). Nevertheless, some evidences, from maize and bean, suggest that domestication triggered roots with larger vessel area (York, GalindoCastañeda, Schussler, \& Lynch, 2015; Peña-Valdivia et al., 2010, Burton, Brown \& Lynch, 2013). Future studies would be needed to test the proportion of vessel and cortex area of wild progenitors and domesticated plants in the context of botanical variation, and the effect of domestication.

Further, the high diameter and low SRL displayed by the roots of wild progenitors are consistent with a recent worldwide meta-analysis, where these attributes were generally associated with fertile environments (Freschet et al., 2017). Indeed, thicker, lower SRL roots may be generally found where plants are less dependent on soil exploitation by fine roots. Finally, larger biomass allocation to the roots of wild progenitors, as compared to that of other wild herbs, is more surprising in light of the typical species in fertile soils but fits the theory of balanced organ biomass and morphology above- versus below-ground, as postulated by Freschet, Kichenin, \& Wardle (2015b). Specifically, since crops and their wild progenitors have relatively higher specific leaf area than average (Milla, Osborne, Turcotte, \& Violle, 2015; Tribouillois et al., 2015), they rely 
less on leaf biomass investment to capture light and could therefore invest more biomass into belowground organs. Further studies comparing the biomass investment below and aboveground in domesticated plants with this in wild herbs would be necessary to test this hypothesis.

The fact that wild progenitors exhibit a root phenotype adapted to agricultural habitats is in line with the Dump Heap hypothesis. This hypothesis suggests that early domestication started with the species growing around human settlements, in anthropogenic environments which are characterized by relatively high nutrient availabilities and disturbance frequencies (Sauer, 1952; Zeven, 1973; Hawkes, 1983). Fast growing and short-lived plants would become more abundant around settlements, would thrive better in early agricultural habitats, and thus would respond better to the early attempts of cultivation and further domestication (Hawkes, 1983; Mercuri, Fornaciari, Gallinaro, Vanin, \& di Lernia, 2018). Although rigorous comprehensive tests are still pending, wild progenitors tend to show specific leaf area and nitrogen content of leaves typical of fast-growing species, when compared with other wild herbaceous plants (Cunniff et al., 2014; Milla, Osborne, Turcotte, \& Violle, 2015). Our screening of root analysis traits is in line with aboveground evidence that wild plants with nutrient acquiring strategies were more successful candidates for domestication by being pre-adapted to the cultivation conditions.

\section{Root traits changed modestly and in idiosyncratic ways after domestication}

We hypothesized that root morphology and allocation would change towards resourceacquisitive strategies alongside domestication processes. Contrary to our hypothesis, we found a wide diversity of root morphology and allocation responses to domestication. 
For most root traits, trait scores decreased in some species or increased in others, which is consistent with a generalized species-specific response, as observed in previous case studies that compared wild progenitors to domesticated species. For example, SRL decreases with domestication in beans (Perez-Jaramillo et al., 2017) but not in maize (Gaudin, Mc Clymont \& Raizada, 2011). Even case studies reporting on the same crop species show opposite responses to domestication depending on growth conditions or the identities of crop varieties under study. For instance, similar allocation to roots was reported for wild progenitors and domesticated species of wheat and maize (Gaudin, McClymont \& Raizada, 2011; Nakhforoosh, Grausgruber, Kaul, \& Bodner, 2014), whereas others found lower allocation to roots in domesticated species for the same two species (Waines \& Ehdaie, 2007; Burton, Brown, \& Lynch, 2013; Szoboszlay et al., 2015; Roucou, Violle, Fort, Roumet, Ecarnot, \& Vile, 2018). Our broader screening together with previous case studies, supports that the effects of domestication on root morphology and allocation are diverse. Nevertheless, to assess the generality of our results, it will be necessary to conduct similar experiments on root traits under more realistic field conditions (Poorter et al. 2016) and under contrasting growth conditions such as competition or fertilization level.

Acknowledging that the response of root traits to domestication is species-specific, we further investigated other explanatory variables that might account for the diversity in the size and directionality of domestication effects among crops. First, we asked whether crops belonging to different functional groups showed contrasting responses to domestication. In accordance with the literature, grasses tended to allocate more biomass to roots than forbs (Fig. 4c; Roumet, Lafont, Sari, Warembourg, \& Garnier, 2008; Poorter et al. 2015; Roumet et al. 2016). Similarly, legumes had lower SRL than 
forbs, also in line with previous evidence (Tjoelker, Craine, Wedin, Reich, \& Tilman, 2005). However, the effect of domestication on root traits was generally insignificant among groups (Table 3, Fig.4), ruling out that functional groups could account for the observed diversity in crop responses to domestication. Similarly, taxonomic affinities have been used to explain variation in root morphology among taxa previously (Kong et al., 2014; Valverde-Barrantes, Freschet, Roumet, \& Blackwood, 2017). However, phylogenetic relationships did not contribute to explain the diversity in crop reactions to domestication (Table S4, Methods S1). Lastly, we explored whether the variation of reactions was explained by variability in domestication processes (timing of the domestication event and organ under focal selection). Interestingly, plant size has increased more in older than in younger crops (Table S4; Fig. S3), which is consistent with a longer selective pressure on size. However, the size of the domestication effect for root traits was not explained by those aspects of the domestication process (Table S4; Figs. S3-4). Further characteristics of the domestication processes such as intensity of the selective efforts or geographical location of domestication event may help to elucidate the observed diversity of root traits responses to domestication.

\section{CONCLUSIONS}

Our comparative analysis revealed that none of the root traits reacted to domestication in accordance with evolution towards faster-growth strategies. Root traits changed during most of the 30 domestication processes surveyed here, but this occurred in diverse directions, depending on the crop species, and irrespective of phylogenetic and functional group affiliations, or of variability in the domestication processes. The diversity of responses to domestication encountered here emphasizes the importance of studying multiple crops with a comparative focus. Finally, the less dense and thicker 
roots with low SRL of crop wild progenitors suggests that the root phenotype of the wild species selected by early farmers were already adapted to fertile and disturbed conditions, thereby supporting the Dump Heap hypothesis. Thus, the adaptation of root phenotypes to fertile soil appears to be largely determined by the choice of wild species by the first farmers rather than by further evolution under domestication.

\section{ACKNOWLEDGMENTS}

We thank J.M. Alonso, J. Margalet and T. de la Fuente for assistance in data gathering. We also thank all public seed banks that provided seeds for the project (complete list in Supplementary Table S1). This work was supported by MINECO (grants CGL201456567-R, BES-2012-054356, PCIN-2014-053).

\section{AUTHOR CONTRIBUTION}

R.M, and N.M-R. conceived the ideas and designed the methodology. Data were contributed by J.M-L, R.M., H.P., G.F., C.R.. Data analyses were discussed by all authors, and performed by N.M-R. N.M-R. led the writing of the manuscript with R.M.. All authors participated to the writing and provided critical reviews of each draft before giving approval for submission of the final version.

\section{DATA ACCESSIBILITY}

The data belonging to the domesticated plants and wild progenitors will be available online as a part of Fine-Root Ecology Database (FRED; http://roots.ornl.gov). The dataset of mean root diameter, root tissue density and specific root length of wild herbs is available as a part of FRED. Finally, the dataset of root mass fraction of wild herbs can be found in Poorter et al. 2015. 


\section{REFERENCES}

Arsenault, J. L., Poulcur, S., Messier, C. \& Guay, R. (1995). WinRHIZO ${ }^{\mathrm{TM}}$, a rootmeasuring system with a unique overlap correction method. HortScience, 30, 906906.

Abbo, S., Pinhasi van-Oss, R., Gopher, A., Saranga, Y., Ofner, I. \& Peleg, Z. (2014). Plant domestication versus crop evolution: A conceptual framework for cereals andgrain legumes. Trends in Plant Science, 19, 351-360.

Bartoń, K. (2013). MuMIn: Multi-model inference. R package version 1.9. 13. The Comprehensive R Archive Network (CRAN), Vienna, Austria.

Bishopp, A. \& Lynch, J.P. (2015). The hidden half of crop yields. Nature Plants, 1, 15117.

Brundrett, M. C. (2002). Coevolution of roots and mycorrhizas of land plants. New phytologist, 154(2), 275-304.

Burton, A.L., Brown, K.M. \& Lynch, J.P. (2013). Phenotypic diversity of root anatomical and architectural traits in Zea species. Crop Science, 53, 1042-1055.

Buuren, S.\& Groothuis-Oudshoorn, K. (2011). mice: Multivariate imputation by chained equations in R. Journal of statistical software, 45(3).

Craine, J.M. (2009). Resource strategies of wild plants. Princeton, NJ: Princeton university press.

Chapin III, F.S. (1980). The mineral nutrition of wild plants. Annual review of ecology and systematics, 11, 233-260.

Cunniff, J., Wilkinson, S., Charles, M., Jones, G., Rees, M. \& Osborne, C.P. (2014). Functional traits differ between cereal crop progenitors and other wild grasses gathered in the neolithic fertile crescent. PLOS ONE, 9.

Delgado-Baquerizo, M., Reich, P.B., García-Palacios, P. \& Milla, R. (2016). 
Biogeographic bases for a shift in crop C: N: $\mathrm{P}$ stoichiometries during domestication. Ecology Letters, 19, 564-575.

Denison, R.F., Kiers, E.T. \& West, S.A. (2003). The Quarterly Review of Biology solutions beyond the reach of natural selection?. Review Literature And Arts Of The Americas, 78, 145-168.

Evans, L.T. (1996) Crop evolution, adaptation and yield. Cambridge university press, Cambridge.

Freschet, G.T. \& Roumet, C. (2017). Sampling roots to capture plant and soil functions. Functional Ecology, 31, 1506-1518

Freschet, G.T., Kichenin, E., Wardle, D.A. (2015b). Explaining within-community variation in plant biomass allocation: a balance between organ biomass and morphology above vs below ground? Journal of Vegetation Science, 26, 431-440.

Freschet, G.T., Swart, E.M. \& Cornelissen, J.H.C. (2015a). Integrated plant phenotypic responses to contrasting above- and below-ground resources: Key roles of specific leaf area and root mass fraction. New Phytologist, 206, 1247-1260.

Freschet, G.T., Valverde-Barrantes, O.J., Tucker, CM, Craine, J.M., McCormack, M.L., Violle, C., ... Roumet, C. (2017). Climate, soil and plant functional types as drivers of global fine-root trait variation. Journal of Ecology, 105 (5), 1182-1196

Gaudin, A.C.M., McClymont, S.A. \& Raizada, M.N. (2011). The nitrogen adaptation strategy of the wild teosinte ancestor of modern maize, Zea mays subsp. parviglumis. Crop Science, 51, 2780-2795.

Gepts, P. (2004). Crop Domestication as a Long-term Selection Experiment. Plant Breeding, 24, 1-44.

Gonzalez-Voyer, A. \& Von Hardenberg, A. (2014). An introduction to phylogenetic path analysis. In Modern phylogenetic comparative methods and their application 
in evolutionary biology (pp. 201-229). Springer, Berlin Heidelberg.

Grace, J. B.\& Bollen, K. A. (2005). Interpreting the results from multiple regression and structural equation models.Bulletin of the Ecological Society of America, 86, 283295.

Hawkes, J. G. (1983). The diversity of crop plants. Harvard University Press, Cambridge.

Johnson, P.C. (2014). Extension of Nakagawa \& Schielzeth's R $^{2}$ GLMM to random slopes models. Methods in Ecology and Evolution, 5, 944-946.

Kembel, S. W., Cowan, P. D., Helmus, M. R., Cornwell, W. K., Morlon, H., Ackerly, D. D., ... \& Webb, C. O. (2010). Picante: R tools for integrating phylogenies and ecology. Bioinformatics, 26, 1463-1464.

Kong, D., Wang, J., Zeng, H., Liu, M., Miao, Y., Wu, H., Kardol, P. (2016). The nutrient absorption-transportation hypothesis: optimizing structural traits in absorptive roots. New Phytologist, 213, 1569-1572.

Kong, D., Ma, C., Zhang, Q., Li, L., Chen, X., Zeng, H. \& Guo, D. (2014). Leading dimensions in absorptive root trait variation across 96 subtropical forest species. New Phytologist, 203(3), 863-872.

Kramer-Walter, K.R., Bellingham, P.J., Millar, T.R., Smissen, R.D., Richardson, S.J., Laughlin, D.C. \& Mommer, L. (2016). Root traits are multidimensional: specific root length is independent from root tissue density and the plant economic spectrum. Journal of Ecology, 104, 1299-1310.

Lambers, H. \& Poorter, H. (1992), Inherent variation in growth rate between higher plants: a search for physiological causes and ecological consequences. Advances in ecological research, 23, 187-261.

Lynch, J.P. \& Brown, K.M. (2012). New roots for agriculture: exploiting the root 
phenome. Philosophical Transactions of the Royal Society B: Biological Sciences, $367,1598-1604$.

Ma, Z., Guo, D., Xu, X., Lu, M., Bardgett, R. D., Eissenstat, D.M., ... Hedin, L.O. (2018). Evolutionary history resolves global organization of root functional traits. Nature, 555, 94.

McKey, D.B., Elias, M., Pujol, B. \& Duputié, A. (2012). Ecological Approaches to Crop Domestication. Biodiversity in agriculture: domestication, evolution, and sustainability, 377.

Mercuri, A. M., Fornaciari, R., Gallinaro, M., Vanin, S., \& di Lernia, S. (2018). Plant behaviour from human imprints and the cultivation of wild cereals in Holocene Sahara. Nature plants, 1 .

Milla, R., De Diego-vico, N. \& Martín-Robles, N. (2013). Shifts in stomatal traits following the domestication of plant species. Journal of Experimental Botany, 64, $3137-3146$.

Milla, R., Osborne, C.P., Turcotte, M.M. \& Violle, C. (2015). Plant domestication through an ecological lens. Trends in Ecology and Evolution, 30, 463-469.

Nakagawa, S. \& Freckleton, R.P. (2008). Missing inaction: the dangers of ignoring missing data. Trends in Ecology and Evolution, 23, 592-596.

Nakhforoosh, A., Grausgruber, H., Kaul, H.P. \& Bodner, G. (2014). Wheat root diversity and root functional characterization. Plant and Soil, 380, 211-229.

Penone, C., Davidson, A.D., Shoemaker, K.T., DiMarco, M., Rondinini, C., Brooks, T.M., ... \& Costa, G.C. (2014). Imputation of missing data in life-history trait datasets: which approach performs the best? Methods in Ecology and Evolution, 5, 961-970.

Peña-Valdivia, C.B., Sánchez-Urdaneta, A.B., Rangel, J.M., Muñoz, J.J., García-Nava, 
R., Velázquez, R.C. (2010). Anatomical root variations in response to water deficit: Wild and domesticated common bean (Phaseolus vulgaris L.). Biological Research, 43, 417-427.

Perez-Jaramillo, J.E., Carrion, V.J., Bosse, M., Ferrao, L.F. V, de Hollander, M., Garcia, A.A.F. et al. (2017). Linking rhizosphere microbiome composition of wild and domesticated Phaseolus vulgaris to genotypic and root phenotypic traits. Isme $J, 1-14$.

Pinheiro, J., Bates, D., DebRoy, S., Sarkar, D.\& Team, R.C. (2015). nlme: Linear and Nonlinear Mixed Effects Models. R package version 3, 1-120.

Poorter, H., Bühler, J., Van Dusschoten, D., Climent, J.\& Postma, J.A. (2012). Pot size matters: A meta-analysis of the effects of rooting volume on plant growth. Functional Plant Biology, 39, 839-850.

Poorter, H., Fiorani, F., Pieruschka, R., Wojciechowski, T., Putten, W. H., Kleyer, M., ... Postma, J. (2016). Pampered inside, pestered outside? Differences and similarities between plants growing in controlled conditions and in the field. New Phytologist, 212, 838-855.

Poorter, H., Jagodzinski, A.M., Ruiz-Peinado, R., Kuyah, S., Luo, Y., Oleksyn, J., ... \& Sack, L. (2015). How does biomass distribution change with size and differ among species? An analysis for 1200 plant species from five continents. New Phytologist, 208, 736-749.

Poorter, H. \& Ryser, P. (2015). The limits to leaf and root plasticity: What is so special about specific root length? New Phytologist, 206, 1188-1190.

Preece, C., Livarda, A., Christin, P.A., Wallace, M., Martin, G., Charles, M., Jones, G., Rees, M. \& Osborne, C.P. (2017). How did the domestication of Fertile Crescent grain crops increase their yields? Functional Ecology, 31, 1-11. 
Preece, C., Livarda, A., Wallace, M., Martin, G., Charles, M., Christin, P.A., ... \& Osborne, C.P. (2015). Were Fertile Crescent crop progenitors higher yielding than other wild species that were never domesticated? New Phytologist, 207, 905-913.

R Core Team (2014). R: A language and environment for statistical computing. R Foundation for Statistical Computing, Vienna, Austria. http://www.R-project.org/.

Reich, P.B. (2014). The world-wide "fast-slow" plant economics spectrum: A traits manifesto. Journal of Ecology, 102, 275-301.

Revell, L.J. (2012). phytools: An R package for phylogenetic comparative biology (and other things). Methods in Ecology and Evolution, 3, 217-223.

Roucou, A., Violle, C., Fort, F., Roumet, P., Ecarnot, M., \& Vile, D. (2018). Shifts in plant functional strategies over the course of wheat domestication. Journal of Applied Ecology, 55, 25-37.

Roumet, C., Birouste, M., Picon- Cochard, C., Ghestem, M., Osman, N., Vrignon- Brenas, S.et al. (2016). Root structure-function relationships in 74 species: evidence of a root economics spectrum related to carbon economy. New Phytologist, 210, 815-826.

Roumet, C., Lafont, F., Sari, M., Warembourg, F. \& Garnier, E. (2008). Root traits and taxonomic affiliation of nine herbaceous species grown in glasshouse conditions. Plant and Soil, 312, 69-83.

Ryser, P. (1996). The Importance of Tissue Density for Growth and Life Span of Leaves and Roots: A Comparison of Five Ecologically Contrasting Grasses. Source: Functional Ecology British Ecological Society Functional Ecology, 10, $717-723$.

Ryser, P. \& Lambers, H. (1995). Root and leaf attributes accounting for the performance of fast-and slow-growing grasses at different nutrient supply. Plant 
and Soil, 170, 251-265.

Sauer, C.O. (1952). Agricultural origins and dispersals. American Geographical Society, New York.

Shipley, B. (2009). Confirmatory path analysis in a generalized multilevel context. Ecology, 90, 363-368.

Singmann, H., Bolker, B.\& Westfall, J. (2015). Afex: analysis of factorial experiments. R package version $0.13-145$.

Smith, B. D. (2007). Niche construction and the behavioral context of plant and animal domestication. Evolutionary Anthropology: Issues, News, and Reviews, 16, 188199.

Smith, B. D. (2011). General patterns of niche construction and the management of 'wild'plant and animal resources by small-scale pre-industrial societies. Philosophical Transactions of the Royal Society B: Biological Sciences, 366, 836848.

Symonds, M. R., \& Blomberg, S. P. (2014). A primer on phylogenetic generalised least squares. In Modern phylogenetic comparative methods and their application in evolutionary biology (pp. 105-130). Springer, Berlin, Heidelberg.

Szoboszlay, M., Lambers, J., Chappell, J., Kupper, J. V., Moe, L.A. \& McNear, D.H. (2015). Comparison of root system architecture and rhizosphere microbial communities of Balsas teosinte and domesticated corn cultivars. Soil Biology and Biochemistry, 80, 34-44.

Tjoelker, M.G., Craine, J.M., Wedin, D., Reich, P.B.\& Tilman, D. (2005). Linking leaf and root trait syndromes among 39 grassland and savannah species. New Phytologist, 167, 493-508.

Tribouillois, H., Fort, F., Cruz, P., Charles, R., Flores, O., Garnier, E., \& Justes, E. 
(2015). A functional characterisation of a wide range of cover crop species: Growth and nitrogen acquisition rates, leaf traits and ecological strategies. PLoS ONE, 10, 1-17.

Turcotte, M.M., Turley, N.E.\& Johnson, M.T.J. (2014). The impact of domestication on resistance to two generalist herbivores across 29 independent domestication events. New Phytologist, 204, 671-681.

Valverde-Barrantes, O.J., Freschet, G.T., Roumet, C. \& Blackwood, C.B. ( 2017). A worldview of root traits: the influence of ancestry, growth form, climate and mycorrhizal association on the functional trait variation of fine-root tissues in seed plants. New Phytologist, 215, 1562-1573.

Waines, J.G.\& Ehdaie, B. (2007). Domestication and crop physiology: Roots of greenrevolution wheat. Annals of Botany, 100, 991-998.

Whitehead, S.R., Turcotte, M.\& Poveda, K. (2016). Domestication impacts on plantherbivore interactions: a meta-analysis. Philosophical Transactions of the Royal Society $B$.

York, L.M., Galindo-Castañeda, T., Schussler, J.R., Lynch, J.P. (2015). Evolution of US maize (Zea mays L.) root architectural and anatomical phenes over the past 100 years corresponds to increased tolerance of nitrogen stress. Journal of Experimental Botany, 66, 2347-2358.

Zanne, A.E., Tank, D.C., Cornwell, W.K., Eastman, J.M., Smith, S.A., FitzJohn, R.G., ... \& Beaulieu, J.M. (2014). Corrigendum: Three keys to the radiation of angiosperms into freezing environments. Nature, 514, 394-394.

Zeven, A.C. (1973). Dr. Th. H. Engelbrecht's views on the origin of cultivated plants. Euphytica, 22, 279-286.

Zohary, D. (2004). Unconcious selection and the evolution of domesticated plants. 
Economic Botany, 58, 5-10.

\begin{tabular}{lclccrr}
\hline Trait & Abbreviation & Definition & \multicolumn{2}{c}{ Units } & \\
\cline { 1 - 4 } Total dry mass & TDM & plant mass & $\mathrm{g}$ & Table & 1. \\
Mean root diameter & MRD & root thickness & $\mathrm{mm}$ & Abbreviatio \\
Root tissue density & RTD & root mass/root volume & $\mathrm{g} / \mathrm{ml}$ & & $\mathrm{ns}$, \\
Specific root length & $\mathrm{SRL}$ & root length/root mass & $\mathrm{m} / \mathrm{g}$ & & definitions \\
Root mass fraction & $\mathrm{RMF}$ & root mass/plant mass & $\mathrm{g} / \mathrm{g}$ & and units of \\
Root length ratio & $\mathrm{RLR}$ & root length/plant mass & $\mathrm{m} / \mathrm{g}$ & and traits
\end{tabular}

measured in the experiment. 
Table 2. Functional group, botanical family, common and botanical names of each of the 30 domesticated species and wild progenitors used in this experiment.

\begin{tabular}{|c|c|c|c|c|}
\hline $\begin{array}{l}\text { Functional } \\
\text { group }\end{array}$ & Family & $\begin{array}{l}\text { Crop } \\
\text { identity }\end{array}$ & Domesticated species & Progenitor species \\
\hline \multirow{9}{*}{ Forb } & Amaranthaceae & Chard & Beta vulgaris L. & Beta vulgaris $\mathrm{L}$. \\
\hline & Asteraceae & $\begin{array}{l}\text { Cardoon } \\
\text { Sunflower }\end{array}$ & $\begin{array}{l}\text { Cynara cardunculus } \mathrm{L} . \\
\text { Helianthus annuus } \mathrm{L} .\end{array}$ & $\begin{array}{l}\text { Cynara cardunculus } \mathrm{L} . \\
\text { Helianthus annuus L. }\end{array}$ \\
\hline & Brassicaceae & $\begin{array}{l}\text { Cabbage } \\
\text { Rucola }\end{array}$ & $\begin{array}{l}\text { Brassica oleracea L. } \\
\text { Eruca vesicaria (L.) Cav. }\end{array}$ & $\begin{array}{l}\text { Brassica oleracea } \mathrm{L} . \\
\text { Eruca vesicaria (L.) Cav. }\end{array}$ \\
\hline & Cucurbitaceae & Cucumber & Cucumis sativus $\mathrm{L}$. & Cucumis sativus L. \\
\hline & Linaceae & Flax & Linum usitatissimum L. & Linum usitatissimum L. \\
\hline & Malvaceae & Cotton & Gossypium hirsutum L. & Gossypium hirsutum L. \\
\hline & \multirow{3}{*}{ Solanaceae } & Chillipepper & Capsicum baccatum $\mathrm{L}$. & $\begin{array}{l}\text { Capsicum baccatum var. pendulum } \\
\text { (Willd.) Eshbaugh }\end{array}$ \\
\hline & & Pepper & Capsicum aппиит $\mathrm{L}$. & $\begin{array}{l}\text { Capsicum annuum var. glabriusculum } \\
\text { (Dunal) Heiser \& Pickersgill }\end{array}$ \\
\hline & & Tomato & Solanum esculentum Dunal & Solanum pimpinellifolium (L.) Mill. \\
\hline \multirow{8}{*}{ Grass } & \multirow{8}{*}{ Poaceae } & Barley & Hordeum vulgare L. & Hordeum spontaneum K.Koch \\
\hline & & Corn & Zea mays L. & Zea mexicana (Schrad.) Kuntze \\
\hline & & Milllet & Pennisetum glaucum (L.) R.Br. & Pennisetum glaucum (L.) R.Br. \\
\hline & & Oat & Avena sativa $\mathrm{L}$ & Avena sterilis $\mathrm{L}$. \\
\hline & & Rye & Secale cereale $\mathrm{L}$. & Secale cereale $\mathrm{L}$. \\
\hline & & Sorghum & Sorghum sudanense (Piper) Stapf & Sorghum bicolor (L.) Moench \\
\hline & & Wheat & Triticum durum Desf. & $\begin{array}{l}\text { Triticum dicoccoides (Körn. ex Asch. } \\
\text { \& Graebn.) Schweinf. }\end{array}$ \\
\hline & & Rice & Oryza sativa $\mathrm{L}$. & Oryza rufipogon Griff. \\
\hline \multirow{11}{*}{ Legume } & \multirow{11}{*}{ Fabaceae } & Bean & Phaseolus lunatus L. & Phaseolus lunatus L. \\
\hline & & Chickpea & Cicer arietinum $\mathrm{L}$. & Cicer reticulatum Ladiz. \\
\hline & & Cowpea & Vigna unguiculata (L.) Walp. & Vigna unguiculata (L.) Walp. \\
\hline & & Lentil & Lens culinaris Medik. & Lens culinaris (Boiss.) Ponert \\
\hline & & Lupin & Lupinus luteus L. & Lupinus luteus L. \\
\hline & & Pea & Pisum sativum L. & $\begin{array}{l}\text { Pisum sativum subsp. elatius } \\
\text { (M.Bieb.) Asch. \& Graebn }\end{array}$ \\
\hline & & Soybean & Glycine $\max$ (L.) Merr. & $\begin{array}{l}\text { Glycine max subsp. soja (Siebold \& } \\
\text { Zucc.) H.Ohashi }\end{array}$ \\
\hline & & $\begin{array}{l}\text { White } \\
\text { clover }\end{array}$ & Trifolium repens $\mathrm{L}$. & Trifolium repens $\mathrm{L}$. \\
\hline & & Faba bean & Vicia faba L. & Vicia narbonensis L. \\
\hline & & Lucerne & Medicago lupulina L. & Medicago lupulina $\mathrm{L}$. \\
\hline & & Vetch & Lathyrus sativus L. & Lathyrus cicera L. \\
\hline
\end{tabular}


Table 3. Effect of domestication on total plant dry mass (TDM) and root traits: mean root diameter (MRD), root tissue density (RTD), specific root length (SRL), root mass fraction (RMF) and root length ratio (RLR), resulted from the linear mixed-effect models. The table shows the $F$ value and significance $(*, P<0.05 ; * *, P<0.01)$ of domestication effect, functional group and the interaction domestication status $\mathrm{x}$ functional group. The variance of the model explained by the fixed effects is indicated by $\mathrm{R}^{2}$ marginal $\left(\mathrm{R}^{2} \mathrm{~m}\right)$. The variances associated with the random effects are indicated by the terms: crop identity, the effect of crop identity on the response of domestication (i.e. random effect on the slope) and the residual variance. Finally, the variance explained by both: random and fixed effects are presented with the $\mathrm{R}^{2}$ conditional $\left(\mathrm{R}^{2} \mathrm{c}\right)$.

\begin{tabular}{|c|c|c|c|c|c|c|c|c|}
\hline & \multicolumn{4}{|c|}{ Fixed effects } & \multicolumn{3}{|c|}{ Random effects } & \multirow{3}{*}{$\mathbf{R}^{2} \mathbf{c}$} \\
\hline & $\begin{array}{c}\text { Domestication } \\
\text { effect (Dom) }\end{array}$ & $\begin{array}{l}\text { Functional } \\
\text { group (FG) }\end{array}$ & Dom x FG & \multirow[t]{2}{*}{$\mathbf{R}^{2} \mathbf{m}$} & $\begin{array}{c}\text { Crop } \\
\text { identity (Crop) }\end{array}$ & Crop x Dom & Residual & \\
\hline & $\mathrm{F}$ & $\mathrm{F}$ & $\mathrm{F}$ & & variance & variance & variance & \\
\hline TDM (g) & $11.15^{* *}$ & 1.82 & 1.84 & 0.14 & 0.33 & 0.28 & 0.14 & 0.85 \\
\hline $\operatorname{MRD}(\mathbf{m m})$ & 2.63 & $7.72 * *$ & 0.67 & 0.29 & 0.04 & 0.02 & 0.01 & 0.91 \\
\hline RTD $(\mathrm{g} / \mathrm{ml})$ & 2.69 & 1.63 & 0.28 & 0.07 & 0.01 & 0.01 & 0.01 & 0.73 \\
\hline SRL (m/g) & 0.04 & $8.60 * *$ & 0.45 & 0.28 & 0.25 & 0.20 & 0.13 & 0.85 \\
\hline RMF (g/g) & 0.08 & $4.94 *$ & 0.22 & 0.15 & 0.02 & 0.03 & 0.02 & 0.73 \\
\hline $\mathbf{R L R}(\mathbf{m} / \mathbf{g})$ & 0.00 & $7.97 *$ & 0.29 & 0.27 & 0.27 & 0.22 & 0.13 & 0.87 \\
\hline
\end{tabular}


Figure 1. (a) Conceptual model of Poorter and Ryser (2015) for root inter-trait relationships, and the effect of nutrient availability. The predicted direction of each effect is indicated with + or - . Nutrient availability increases total dry mass and reduces root mass fraction. Larger plants generally have a thicker mean root diameter, but their effect on root tissue density is less pronounced. Through the predicted increase of mean root diameter, the specific root length decreases. As a consequence, the root length ratio decreases, achieving less root length per unit of total plant mass. (b) Fit of the domesticated plant and wild progenitor dataset to the conceptual model (a) using phylogenetic path analysis. Here, the nutrient availability effect is replaced by the domestication effect, as argued in the Introduction Section. Standardized path coefficients (obtained from phylogenetic generalized least squares models) are shown in each arrow. Negative paths coefficients are indicated with dashed arrows. Statistically significant paths $(P<0.05)$ are marked in bold and an asterisk. The $P$ value associated to the C-statistic is obtained using the $P$ values of the conditional independencies tested (see Shipley, 2002). $P>0.05$ indicates that the data fits the model.

(a)

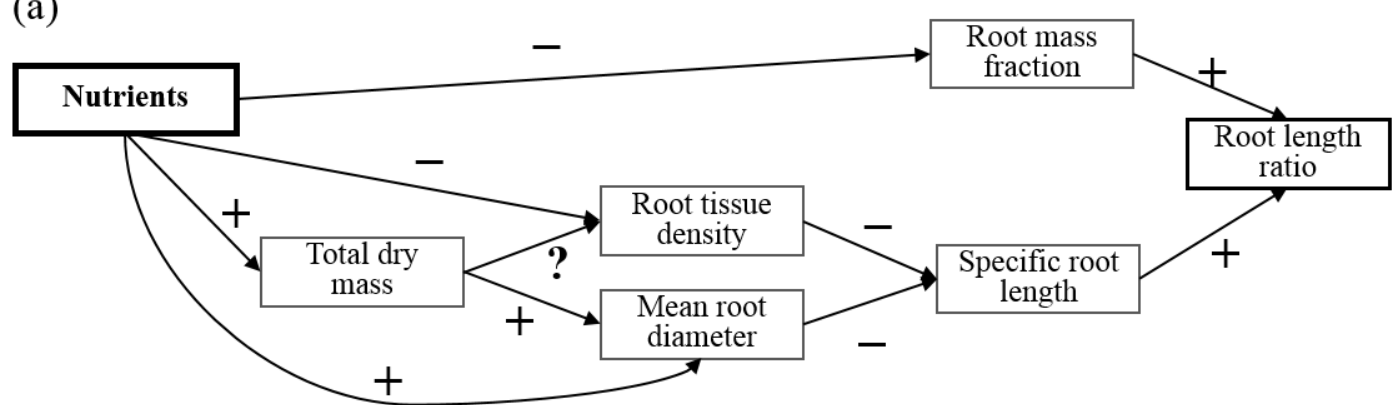

(b)

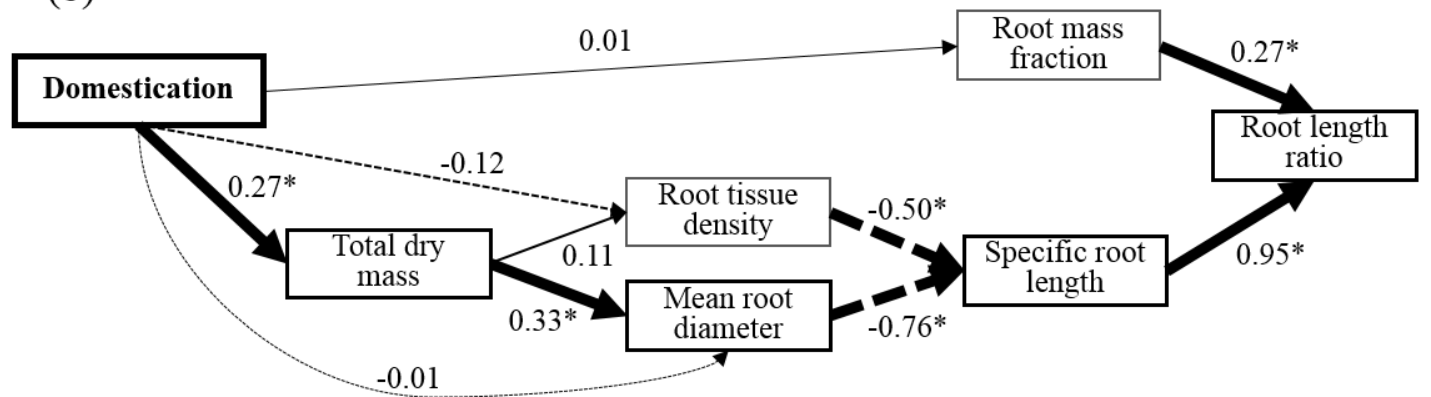

C statistic $=20.56, p=0.55$

This article is protected by copyright. All rights reserved. 
Figure 2. The domesticated and wild progenitor species of this study in the context of botanical diversity of four root traits: mean root diameter (a), root tissue density (b), specific root length (c) and root mass fraction (d). The symbols represent the mean score of a given species: domesticated (dark circles), wild progenitors (dark triangles) and global database (light circles), sorted by phylogeny (phylogenetic tree on the left side). Colors of the symbols correspond to functional group: forbs (blue), grasses (green) and legumes (yellow). The total number of species is indicated on top of each plot. Statistically significant differences (*, $P<0.05$; ns, $P>0.05)$ among domesticated (D), wild progenitor (W) and other wild species $(\mathrm{O})$, extracted from post hoc test, are

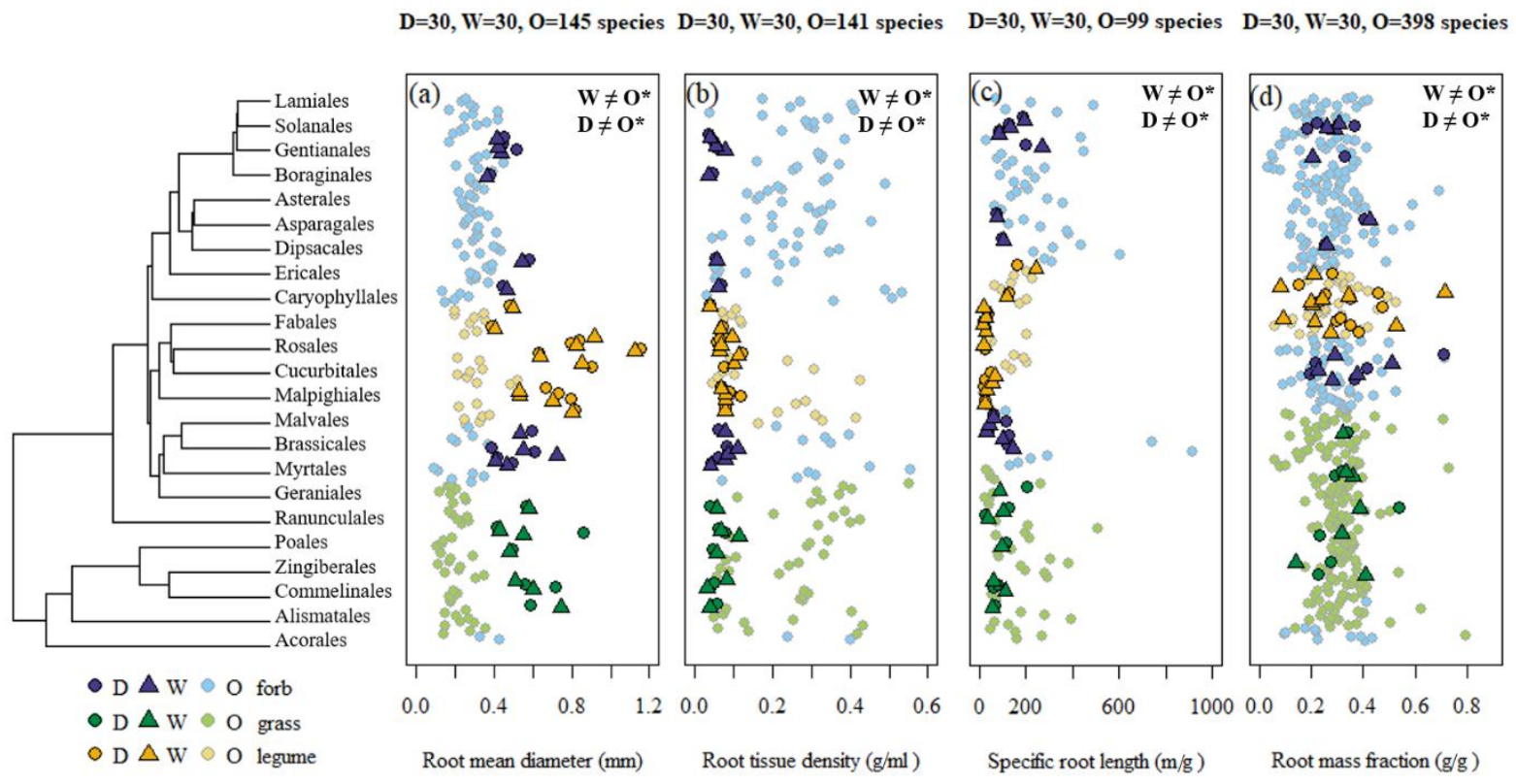

displayed in the upper left corner. 
Figure 3. Effect of domestication on on total dry mass (TDM, a), mean root diameter (MRD, b), root tissue density (RTD, c), specific root legth (SRL, d), root mass fraction (RMF, e) and root length ratio (RLR, f). The symbols show the domestication effect size estimated by Hedges ${ }^{\prime} \mathrm{G}$ and $95 \%$ confidence intervals for each crop. The overall effect of domestication on each trait, taken from results of mixed models (Table 3 ), is indicated in each graph with a black diamond. Colors of the points correspond to functional group: forb (blue), grass (green) and legume (yellow) and the shapes indicate the botanical families.
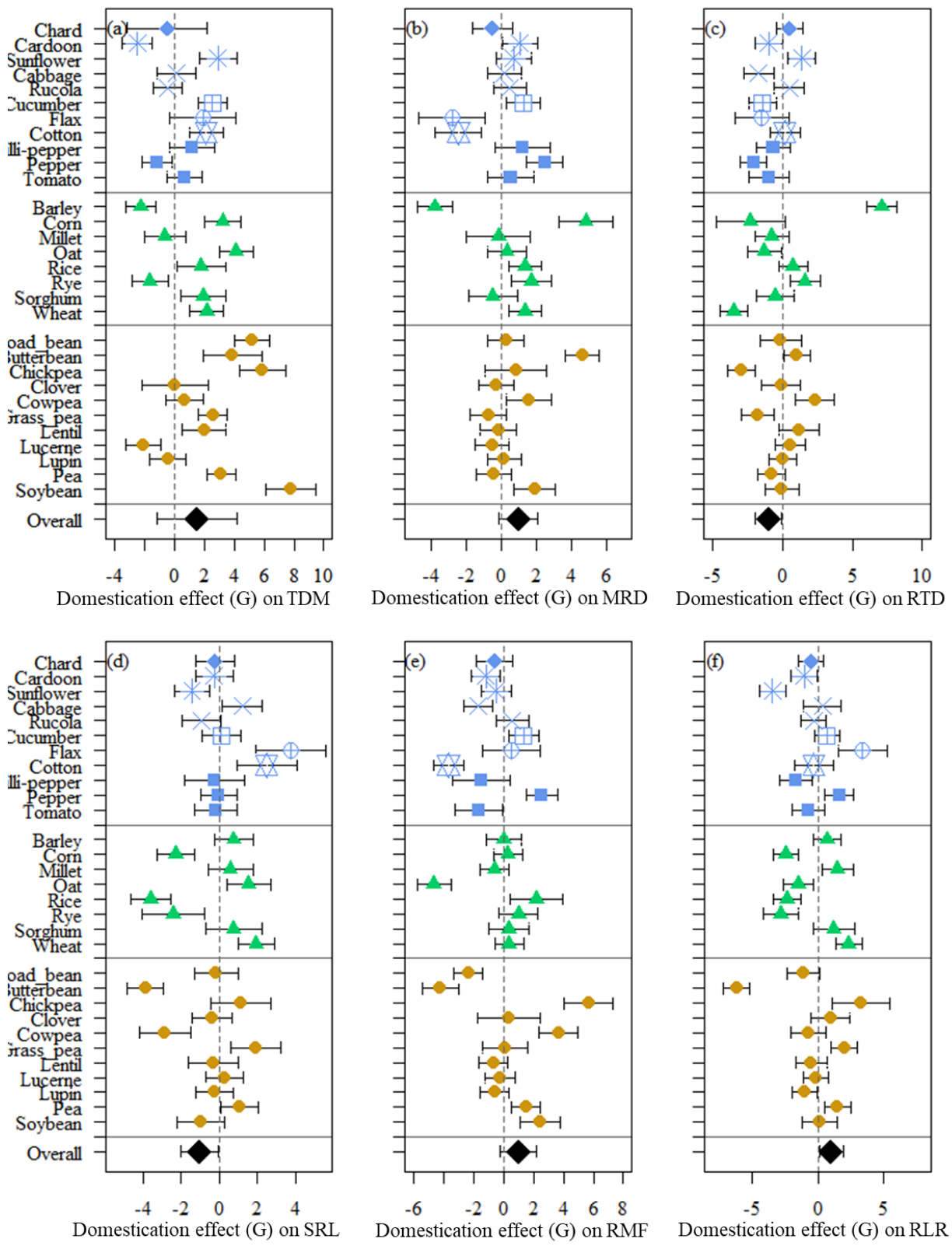
Figure 4. Evolution of total plant dry mass (a) and root traits: mean root diameter (b), root tissue density (c), specific root length (d), root mass fraction and root length ratio (f) under domestication, depending on functional group affiliation: forbs (blue squares), grasses (green triangles) and legumes (yellow dots). The symbols and error bars show the estimated least squares values means and 95\% confidence limits, respectively, obtained by mixed effect models. The significances $(*, P<0.05 ; * *, P<0.01)$ of domestication and functional group, as taken from table 2 , are displayed in the right corner of each graph.
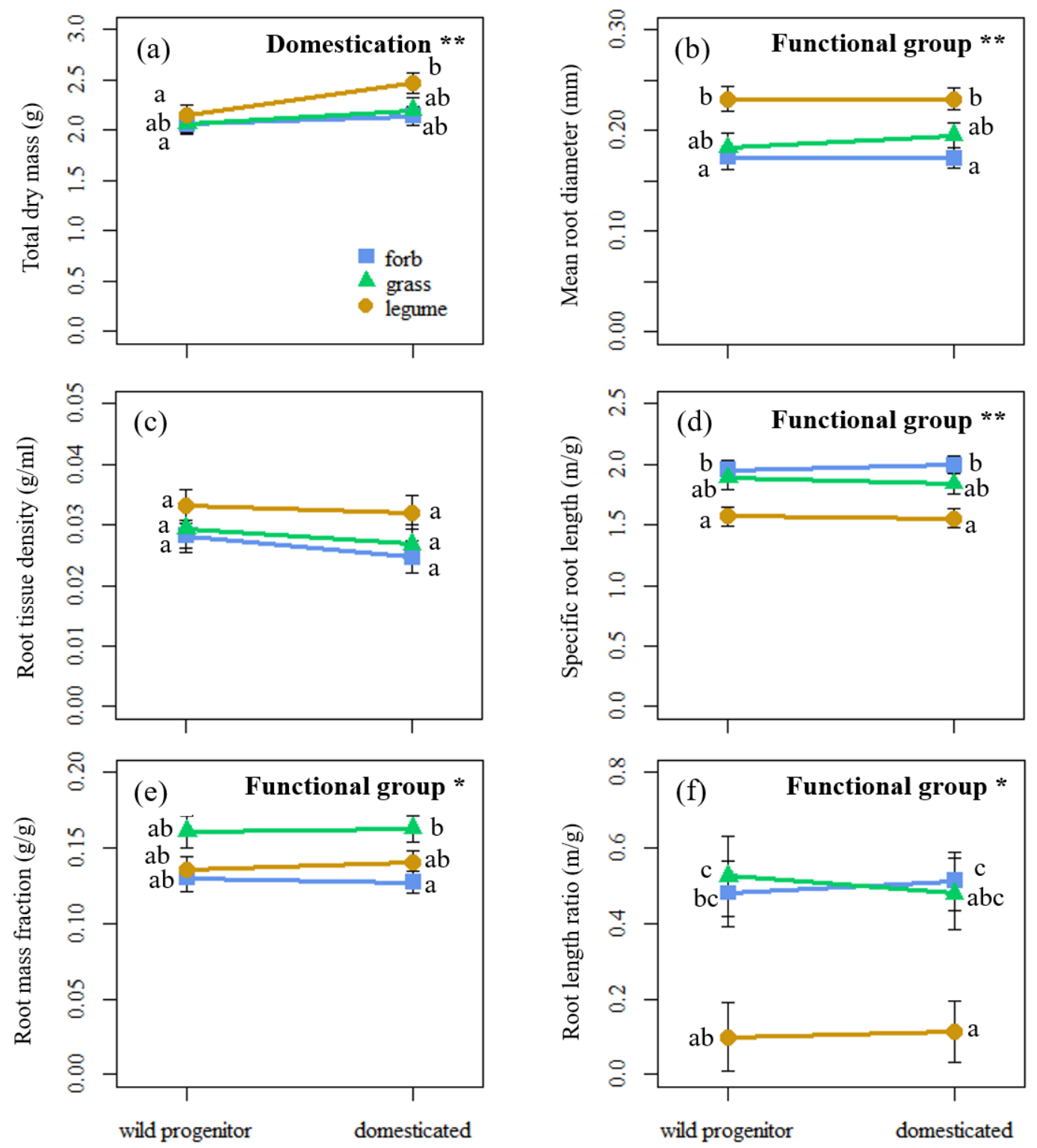
Figure 5. Effect sizes of the direct (grey bars), indirect (green bars), and total effects (sum of direct and indirect effects, black diamond) of domestication on total plant dry mass, mean root diameter, root tissue density, specific root length, root mass fraction, and root length ratio. All the effects were calculated from standardized path coefficients, taken from Fig. 1b.

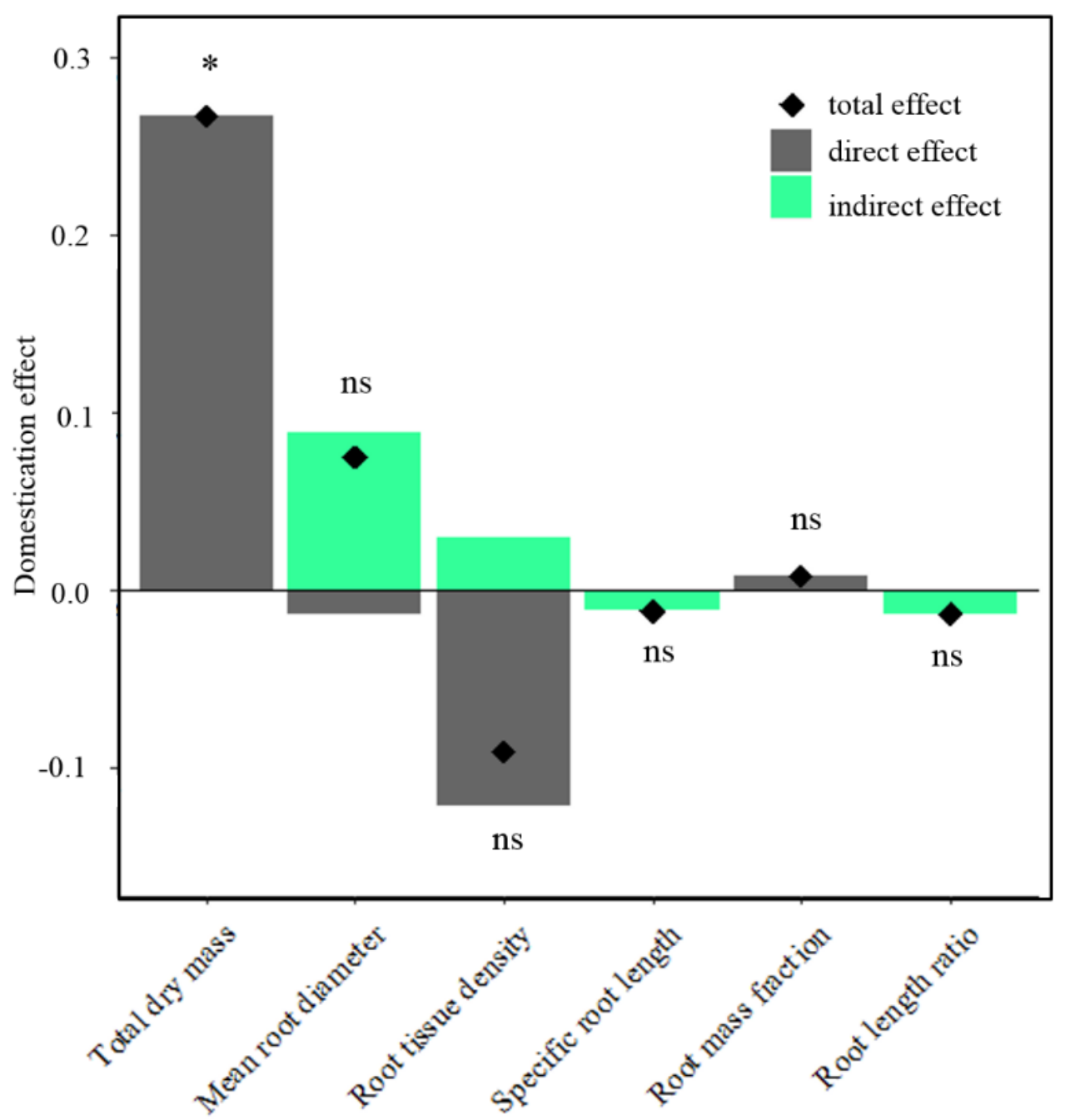

